\title{
TO ASSESS EFFECTIVENESS OF PLAN TEACHING PROGRAMME ON NATIONAL ACCREDITATION BOARD FOR HOSPITALS AND HEALTH CARE PROVIDERS (NABH) GUIDELINES AMONG NEWLY RECRUITED STAFF NURSES AT KRISHNA HOSPITAL, KARAD
}

\author{
Kavita Sanjay Kapurkar1, Sandhya Anil Jagadale2, Rohini Vimalakar Babar ${ }^{3}$
}

${ }^{1}$ ANS/Nurse Educator, Krishna Institute of Nursing Sciences, Karad, Satara, Maharashtra.

${ }^{2}$ ANS/Nurse Educator, Krishna Institute of Nursing Sciences, Karad, Satara, Maharashtra.

${ }^{3}$ Nursing Superintendent, Krishna Institute of Nursing Sciences, Karad, Satara, Maharashtra.

\section{ABSTRACT}

The continual improvement of service quality in healthcare units has become a prime consideration to ensure patient satisfaction across the world in the modern economic scenario. In India, health sector is one of the largest and fastest growing sector in which both the private and government care providers and hospitals put much emphasis on quality improvement and patient satisfaction. National Accreditation Board of Hospitals and Healthcare Providers (NABH) along with Quality Council of India provided the criteria based on which quality standard of hospitals is determined. The study was conducted on 51 newly recruited staff nurses at Krishna Hospital, Karad. An evaluator survey approach was considered. Study design was used one group pre-test, post-test design. Purposive sampling technique was used.

\section{RESULTS}

The study was conducted on 51 newly recruited staff nurses at Krishna Hospital, Karad. An evaluator survey approach was considered. Study design was used one group pre-test, post-test design. Purposive sampling technique was used.

\section{CONCLUSION}

Study concludes majority of newly recruited nursing staff having $19.38 \%$ average knowledge and $17.85 \%$ having average practice towards NABH guidelines. Knowledge and practice score of newly recruited nursing staff between the pre-test and post-test was highly significant.

\section{OBJECTIVES}

1) To assess newly recruited staff nurses knowledge and practice towards NABH guidelines. 2) To find an association of knowledge and practice between pre-test and post-test of PTP programme on NABH guidelines.

\section{KEYWORDS}

Knowledge, Practice, Accreditation, Staff Nurses.

HOW TO CITE THIS ARTICLE: Kapurkar KS, Jagadale SA, Babar RV. "To assess effectiveness of plan teaching programme on National Accreditation Board for Hospitals and Health Care Providers (NABH) guidelines among newly recruited staff nurses at Krishna Hospital, Karad." Journal of Evolution of Medical and Dental Sciences 2015; Vol. 4, Issue 103, December 24;

Page: 16830-16834, DOI: $10.14260 /$ jemds/2015/2527

\section{INTRODUCTION}

"Accreditation is usually a voluntary program, sponsored by a Nongovernmental Agency (NGO), in which trained external peer reviewers evaluate a health care organization's compliance with pre-established performance standards. Accreditation addresses organizational, rather than individual practitioner capability or performance. Unlike licensure, accreditation focuses on continuous improvement strategies and achievement of optimal quality standards rather than adherence to minimal standards intended to assure public safety." 1

Accreditation formally started in the United States with Joint Commission on Accreditation of Healthcare Organizations (JCAHO) in 1951.

- Canada and Australia in the 1960s and 1970s.

- $\quad$ Europe in the 1980s.

- Accreditation programs spread all over the world in the 1990s.

Financial or Other, Competing Interest: None.

Submission 01-12-2015, Peer Review 02-12-2015,

Acceptance 18-12-2015, Published 22-12-2015.

Corresponding Author:

Kavita Sanjay Kapurkar,

Krishna Institute of Nursing Sciences,

Karad, Satara,

Maharashtra.

E-mail: kavitakapurkar@gmail.com

DOI: $10.14260 /$ jemds/2015/2527
India: 2005. More than 70 countries have accreditation models. Some accreditation models are international.

Since the quality is crucial factor in health care initiatives to address the quality of health care have become a worldwide phenomenon. A commitment to quality enhancement throughout the whole of health care system involving all professional and service group is essential to ensure that high quality in the health care achieved while minimizing the inherent risks associated with modern health care delivery. One method that is accreditation system. The focus of accreditation is on continuous improvement in organizational and clinical performance of health services and not just the achievement of certificate or award or merely assuring compliance with minimum acceptable standards. ${ }^{2}$

Rapidly rising cost in healthcare is an increasing cause of concern across the world. Indian healthcare is also experiencing a change with increasing focus on better quality of medical care services. With a large section of healthcare practitioners in the private sector, the government has realized the need to improve medical care services and has stepped into regulate the quality of medical care services by introduction of various quality accreditation norms like the NABH and NABL.

As per available information, the healthcare spending per capita per annum in India was about $\$ 109$ with total healthcare spending in the range of $4.9 \%$ of the country's GDP. ${ }^{3}$ Most of the spending occurs from the private sector with public sector contributing to a mere $\$ 19$ per capita per annum. Concurrently, the average spending per capita per annum in the United States 
during the same timeframe was approximately $\$ 4271$, whilst United Kingdom the spending was $\$ 1675$. These figures clearly indicate that healthcare in India is fairly cheaper, a strong reason for a growing medical tourism market in the country. However, when compared with paying power parity and affordability, the cost of medical care is escalating. It is worthwhile to note that as per World Bank estimates more than $44 \%$ of Indian population earns less than one dollar a day.

As per the Finance Ministry, the overall inflation rate in India was about 9.4 percent during April-December 2010, while inflation in medical expenses was in excess of 10 percent for the fourth year in a row. ${ }^{4}$ There are several other factors that have been contributing to the escalation in cost of medical care. These factors include increasing demand for medical care services with consistently limited supply, increased penetration of health insurance, improvement in medical technology with new innovations improving diagnostic capabilities and increasing dependence of doctors on diagnostic procedures. Increasing demand for quality in medical care services plays a critical role in increasing the overall cost of medical care services.

While empirical evidence suggests that there is an increasing demand for healthcare services across India, affordability remains a pertinent issue. This has resulted in market segmentation, where on one hand there is an increasing demand for quality medical care services, while on the other hand there is a demand for medical care services at affordable cost. ${ }^{5}$ The demand for the latter has inevitably resulted in poor quality of medical care services with poor health outcomes.

It is simple to compute the direct costs for various medical services; however, to compute the cost of quality is not only difficult but rather elusive, which has resulted in over dependence on subjective criterions. ${ }^{6}$ Various modalities like manpower ratios, infrastructure, medical technological capabilities, accreditation and quality assurance policies and mortality rates have been considered as quality indicators and have been used to evaluate the quality of healthcare services. The paper attempts to explore the implication of these quality indicators on the direct expenses incurred by patients whilst seek healthcare services across India.

Economic growth has a positive effect on health of people by increasing their level of income.

(Gangadharan, 2008). ${ }^{7}$ In the age of globalization and liberalization, India has achieved certain growth in its economy by increasing the standard of living of people, which increases the consumers' expectation on the quality in healthcare service (Pahuja and Vohra, 2012, Kumaraswamy, 2012). ${ }^{8}$ In present situation, continuous improvement of quality of healthcare becomes much important for any healthcare providers by improving infrastructure with technological upgradation (Pahuja and Vohra 2012, Rao 2012, Itumalla 2012.8.

According to Purbey et al. (2006), the healthcare sector is the fastest and largest growing sector in India, where Government gives much emphasis on improvement of quality of its service. In the present socio-economic environment, patients in India are aware of their rights as consumers of health services and demand quality healthcare. In this context, all the healthcare providers should have closer look at the perception of their patients and provide quality healthcare to meet up their expectation (Itumalla, 2012). ${ }^{8}$ Sharma and Narang (2011). ${ }^{9}$ in their study, found that with the improvement of income and education of Indian people, their expectation for quality healthcare service has also been increasing. Therefore, it is primary task of all the healthcare providers in India to provide quality medical service to their patients.

\section{NEED FOR STUDY}

Hospital Accreditation is a public recognition by a National Healthcare Accreditation Body, of the achievement of accreditation standards by a Healthcare Organization, demonstrated through an independent external peer assessment of that organization's level of performance in relation to the standards. In India, Health System currently operates within an environment of rapid social, economical and technical changes. Such changes raise the concern for the quality of health care. Hospital is an integral part of health care system. Accreditation would be the single most important approach for improving the quality of hospitals. Accreditation is an incentive to improve capacity of National Hospitals to provide quality of care. National accreditation system for hospitals ensure that hospitals whether public or private, national or expatriate play their expected roles in National Health System.

Uniform accreditation system for healthcare industries consists of a National Accreditation Board of Hospitals and Healthcare Providers (NABH), which is responsible for drafting the rules and standards to be maintained by the healthcare institutes.

The next decade shall see a great change in the health care sector and there is a need for standardization of health care delivery at all levels, which at the moment is lacking in India. The standardization can come if we adopt some sort of uniform accreditation. This asks for an assessment on the attitude of medical staff toward accreditation and then the knowledge on accrediting standards. This study is conducted with the objectives to identify the knowledge and practice level of newly recruited staff on accreditation level on NABH standards. ${ }^{10}$

\section{REVIEW OF LITERATURE}

The National Accreditation Board for Hospitals and Healthcare Providers (NABH) Standards is today the highest benchmark standard for hospital quality in India. Though developed by the Quality Council of India on the lines of International Accreditation Standards like the JCI, ACHS and the Canadian Hospital Accreditation Standards, the NABH is however seen as a more practical set of Standards, topical and very relevant to India's unique healthcare system requirements.

\section{NABH Standards \\ Patient Centered Standards}

1. Access, Assessment and Continuity of Care (AAC).

2. Care of Patients (COP).

3. Management of Medication (MOM).

4. Patient Rights and Education (PRE).

5. Hospital Infection Control (HIC).

\section{Organization Centered Standards}

1. Continuous Quality Improvement (CQI).

2. Responsibilities of Management (ROM).

3. Facility Management and Safety (FMS).

4. Human Resource Management (HRM).

5. Information Management System (IMS).

Within just 2 years of its launch, the Indian Accreditation Standards, the NABH was accepted by ISQUa, the International Society for Quality Assurance in Healthcare as an International Accreditation on par with the world's best. ${ }^{11}$

More important than the infrastructure, it is essential to know if the hospital has a documented process for its healthcare activities. Patient care not only involves the core clinical care, but also other support activities like requisition of tests, medicines, nurse doctor coordination, infection control practices, training and so on. These need to run seamlessly in the background to provide the best experience to the patient and the relative. ${ }^{12}$ 
The changing health care environment with revised hospital accreditation guidelines have sharpened the clinical and administrative hospital staff's concern for evaluating the quality of care they provide. Clinicians now see accreditation standards as a framework by which organizational processes will be improved and their patients will receive better care. Physicians and administrators now must face the challenge of establishing comprehensive and vigorous systems of quality assurance and learn to avoid the traps that impede implementation of such systems. Quality assurance is a very simple process that deals with finding problems and fixing them.

A comprehensive definition of quality health care would be, "The optimal achievable result for each patient, the avoidance of physician-induced (iatrogenic) complications, and attention to patient and family needs in a manner that is both cost effective and reasonably documented".13

According to Karen $\mathrm{H}$ Timmons. ${ }^{14}$ accreditation is recognised as a framework to integrate a quality management system while reducing risk and requires a systematic assessment of hospitals against explicit standards.

\section{Benefits of NABH Accreditation}

According to CorpAxis Certification India Private Limited.[15] It results in high quality of care and patient safety.

It results in a consistent protection of rights of patients and medical ethics.

It stimulates continuous improvement and enables a hospital to demonstrate commitment to quality care.

It raises community confidence in the services provided by the hospital. It also provides opportunity to healthcare units to benchmark with the best.

It provides continuous learning, good working environment, leadership, and above all ownership of clinical processes.

It improves overall professional development of clinicians and paramedical staffs and provides leadership for quality improvement within medicine and nursing.

It provides an objective system of empanelment by insurance and other third parties.

It brings higher level of confidence among patients and specifically corporates for delivering quality healthcare services.

Dr. Akash Rajpal. ${ }^{16}$ Senior Manager Medical Services and the NABH accreditation coordinator said: "The process of preparing for NABH has improved the overall quality of the patient care services. Doctors, nurses and even the housekeeping staff understand the importance of providing the care at best of their abilities and are now more responsive and accountable. Strong emphasis was laid on strengthening policies, procedures and protocols, reviewing performance through patient satisfaction, conducting audits and training the staff including clinicians, nursing, management and outsourced staff. The hospital came through working as a team with a lot of passion for excellence."

In a study conducted by El-Jardali F, Jamal D, Dimassi H, Ammar W, Tchaghchaghian V. ${ }^{17}$ on the impact of hospital accreditation on quality of care: perception of Lebanese nurses and it was observed that nurses perceived an improvement in quality during and after the accreditation process. Lebanese nurses felt hospital accreditation is a good tool for improving quality of care. In order to ensure that accreditation brings effective quality improvement practices, there is a need to assess quality based on patient outcome indicators.

According to a study conducted by Gentile S et al. ${ }^{18}$ on accreditation knowledge acquired by personnel in the Marseille Hospital, the results demonstrate that the knowledge about accreditation seems to be well integrated with only 7 of the professionals being unaware of the accreditation programme and $58 \%$ of them associating the accreditation process with an administrative procedure. Grouping the staff's responses according to professional category has shown to have almost no influence on the results. The level of overall knowledge is greater in more highly trained personnel $(p<0.05)$, but there was a poor level of knowledge regarding the internal organizational structures that existed; $75 \%$ of the health professionals thought that communication about accreditation was insufficient.

A study on knowledge and awareness of standard precautions among health care workers at Nizam's Institute of Medical Sciences, Hyderabad; Mudedla S Tej, WL Reddy, KT Sowribala, M Aim: The aim was to assess the knowledge and awareness of standard precautions among heath care workers, that is doctors, nurses and technicians. It was observed that 96(53.3\%) respondents are very knowledgeable and 84(46.7\%) were somewhat knowledgeable. In the very knowledgeable category, there were 38 doctors, 24 nurses and 34 technicians; 48(57.1\%) males and 48(50\%) female respondents were found to be very knowledgeable.

With respect to length of service, $21(53.8 \%)$ respondents in 0-5 years of service category, $18(60 \%)$ in $5-10$ years category and $57(48.7 \%)$ in $>10$ years category were found to be very knowledgeable. Conclusions: Knowledge of standard precautions was highest among doctors (63.3\%) followed by technicians $(56.6 \%)$ and nurses $(40.0 \%)$. There is a significant difference in knowledge and awareness of standard precautions among studied health care professionals $(\mathrm{P}=0.031)$. Knowledge and awareness of standard precautions did not vary significantly between males and females $(\mathrm{P}>0.05)$. There is no significant difference in knowledge and awareness of standard precautions among groups with respect to length of service $(\mathrm{P}>0.05){ }^{19}$

\section{MATERIAL METHOD}

The study was conducted on 51 newly recruited staff nurses at Krishna Hospital, Karad. An evaluatory survey approach was considered. Study design was used one group pre-test, posttest design. Purposive sampling technique was used. The instrument used for data collection was a Questionnaire of knowledge and practice.

\section{RESULTS}

Analysis and interpretation of the data was based on the projected objectives of the study viz.,

1. To assess staff nurses knowledge and practice towards NABH guidelines.

2. To find an association of knowledge and practice between pre-test and post-test of PTP programme on NABH guidelines.

\begin{tabular}{|c|c|c|c|}
\hline $\begin{array}{c}\text { SI. } \\
\text { No. }\end{array}$ & Variables & Frequency & Percentage \% \\
\hline 1 & \multicolumn{2}{|c|}{ Age in yrs } & \\
\hline & $21-23$ & 46 & 23.46 \\
\hline & $24-27$ & 4 & 2.04 \\
\hline & $28-30$ & 1 & 0.51 \\
\hline \multirow[t]{3}{*}{2} & \multicolumn{2}{|c|}{ Sex } & \\
\hline & Male & 11 & 5.61 \\
\hline & Female & 40 & 20.4 \\
\hline \multirow[t]{4}{*}{3} & \multicolumn{2}{|c|}{$\begin{array}{l}\text { Education } \\
\end{array}$} & \\
\hline & RGNM & 3 & 1.53 \\
\hline & PB.B.Sc & 5 & 2.55 \\
\hline & B.BSc & 43 & 21.93 \\
\hline \multirow[t]{5}{*}{4} & \multicolumn{2}{|c|}{ Source of Information } & \\
\hline & T.V. & 7 & 3.57 \\
\hline & Internet & 2 & 1.02 \\
\hline & Journal & 3 & 1.53 \\
\hline & Educator & 39 & 19.89 \\
\hline
\end{tabular}

Table 1: Distribution of newly recruited staff nurses according to frequency and percentage of demographic variable. $N=51$ 
The data presented in Table no. 1 reveals that majority $23.46 \%$ of newly recruited nursing staff belongs to age group of $21-23$ years. Maximum staffs $20.4 \%$ were female, majority $21.93 \%$ staffs were educated basic BSc and collecting the health information from educator.

\begin{tabular}{|c|c|c|}
\hline Categorization & Knowledge (\%) & Practice (\%) \\
\hline Good & $8(4.08)$ & $1 \%(0.51)$ \\
\hline Average & $33(16.83)$ & $8 \%(4.08)$ \\
\hline Poor & $10(5.1)$ & $42(51)$ \\
\hline
\end{tabular}

Table no. 2 indicates that in pre-test newly recruited nursing staff having majority of $16.83 \%$ average knowledge and majority of $51 \%$ having poor practice of NABH guidelines.

\begin{tabular}{|c|c|c|}
\hline Categorization & Knowledge \% & Practice \% \\
\hline Good & $12(6.12)$ & $8(4.08)$ \\
\hline Average & $38(19.38)$ & $35(17.85)$ \\
\hline Poor & $1(0.51)$ & $8(4.08)$ \\
\hline $\begin{array}{c}\text { Table 3: Categorization according to post-test } \\
\text { Knowledge and Practice score of newly recruited nursing } \\
\text { staff } \mathbf{N}=\mathbf{5 1}\end{array}$ \\
\hline
\end{tabular}

Table no. 3 indicates that in post-test newly recruited nursing staff having majority of $19.38 \%$ average knowledge and majority of $17.85 \%$ having average practice of $\mathrm{NABH}$ guidelines.

\begin{tabular}{|c|c|c|c|c|c|}
\hline & Mean & SD & $\begin{array}{c}\text { T } \\
\text { value }\end{array}$ & df & P. Value \\
\hline Pre-test & 14.58 & 5.5 & 1.211 & 04396 & $>0.1$ \\
\hline Post-test & 26.13 & 6.6 & & & $>0.1$ \\
\hline Table 4: Pre-test and post-test knowledge and practice \\
score of newly recruited nursing staff $\mathbf{N}=\mathbf{5 1}$
\end{tabular}

Table no. 4 reveals that there was no significant difference between pre-test and post-test knowledge and practice of newly recruited staff nurses towards NABH guidelines and statistically not significant because $t=1.2111$ with one degree of freedom.

\begin{tabular}{|c|c|c|c|c|c|}
\hline Knowledge & Mean & SD & $\begin{array}{c}\text { T } \\
\text { value }\end{array}$ & df & $\begin{array}{c}\text { P } \\
\text { Value }\end{array}$ \\
\hline Pre-test & 11.27 & 5.099 & \multirow{2}{*}{8.003} & 50 & $<$ \\
\hline Post-test & 18.86 & 4.875 & & 0.0001 \\
\hline Table 5: Knowledge score of pre-test and post-test \\
of newly recruited nursing staff $\mathbf{N = 5 0}$ \\
\hline
\end{tabular}

Table no. 5 shows that knowledge score of newly recruited nursing staff between the pre-test and post-test was highly significant as the $\mathrm{P}$ value is $<0.0001$.

\begin{tabular}{|c|c|c|c|c|c|}
\hline Practice & Mean & SD & $\begin{array}{c}\text { T } \\
\text { value }\end{array}$ & df & P Value \\
\hline Pre-test & 4 & 1.414 & \multirow{2}{*}{8.368} & 50 & $<0.0001$ \\
\hline Post-test & 7.98 & 3.140 & & \\
\hline Table 6: Practice score of pre-test and post-test of newly \\
recruited nursing staff $\mathbf{N = 5 1}$ \\
\hline
\end{tabular}

Table no. 6 shows that practice score of newly recruited nursing staff between the pre-test and post-test was highly significant as the $\mathrm{P}$ value is $<0.0001$.

\section{DISCUSSION}

The present study found that newly recruited nursing staff having majority of $19.38 \%$ average knowledge and majority of
$17.85 \%$ having average practice of NABH guidelines. There was no significant difference between pre-test and post-test knowledge and practice of newly recruited staff nurses towards NABH guidelines and statistically not significant. Knowledge score of newly recruited nursing staff between the pre-test and post-test was highly significant practice score of newly recruited nursing staff between the pre-test and posttest was highly significant.

Similar study conducted by Gentile S. et al.[18] on accreditation knowledge acquired by personnel in the Marseille Hospital, the results demonstrate that the knowledge about accreditation seems to be well integrated, with only 7 of the professionals being unaware of the accreditation programme and 58\% of them associating the accreditation process with an administrative procedure. Grouping the staff's responses according to professional category has shown to have almost no influence on the results. The level of overall knowledge is greater in more highly trained personnel $(\mathrm{p}<0.05)$, but there was a poor level of knowledge regarding the internal organizational structures that existed.

One more similar study on knowledge and awareness of standard precautions among health care workers at Nizam's Institute of Medical Sciences, Hyderabad; Mudedla, S Tej, WL Reddy, KT Sowribala, M Aim: The aim was to assess the knowledge and awareness of standard precautions among heath care workers that is doctors, nurses and technicians. It was observed that $96(53.3 \%)$ respondents are very knowledgeable and $84(46.7 \%)$ were somewhat knowledgeable. In the very knowledgeable category, there were 38 doctors, 24 nurses and 34 technicians; 48(57.1\%) males and $48(50 \%)$ female respondents were found to be very knowledgeable.

With respect to length of service, $21(53.8 \%)$ respondents in $0-5$ years of service category, $18(60 \%)$ in $5-10$ years category and $57(48.7 \%)$ in $>10$ years category were found to be very knowledgeable. Conclusions: Knowledge of standard precautions was highest among doctors (63.3\%) followed by technicians $(56.6 \%)$ and nurses $(40.0 \%)$. There is a significant difference in knowledge and awareness of standard precautions among studied health care professionals $(\mathrm{P}=$ 0.031 ). Knowledge and awareness of standard precautions did not vary significantly between males and females $(P>0.05)$. There is no significant difference in knowledge and awareness of standard precautions among groups with respect to length of service $(\mathrm{P}>0.05) .{ }^{19}$

\section{CONCLUSION}

Study concludes majority of newly recruited nursing staff having $19.38 \%$ average knowledge and $17.85 \%$ having average practice towards NABH guidelines. Knowledge and practice score of newly recruited nursing staff between the pre-test and post-test was highly significant.

\section{FUTURE SCOPE}

\section{NURSING IMPLICATION}

The findings of this study have implications for nursing practice, nursing education, nursing administration and nursing research.

\section{NURSING PRACTICE}

The knowledge and practice of NABH accreditation and standard guidelines needs to be provided to all nursing personnel and can be continued in the hospital.

\section{NURSING ADMINISTRATION}

The finding of the study will help the nurse administrator to organize more workshops, panel discussion, short term refresher courses and health education programme for nurses. 


\section{NURSING RESEARCH}

Research suggests that accreditation of hospital is a good way to provide standardization in treatment.

\section{REFERENCES}

1. Rooney AL, van Ostenberg PR. Licensure, Accreditation and Certification: Approaches to Health. Bethesda: Quality Assurance $\quad$ Project 1999 www.qaproject.org/indexl.html.

2. Jyothi, Bidhan G. Developing national accreditation systems: Needs challenges and future directions. Express Health care Management 2005.

3. Care Continuum Alliance (Home Page on the Internet). USA. India Healthcare Spending; 2009 (updated 2009 December 6; cited 2011 May 21) available from:http://dmaa.pbworks.com/w/page/17960771/In dia $\% 20 \% 20$ Health\%20Care $\% 20$ Financing\%20and $\% 20$ Expenditure)

4. Medical bills rising faster than inflation. Business Today, 2010, March 31: Sect 2.

5. Shah U, Mohanty R. Private Sector in Indian Healthcare Delivery: Consumer Perspective and Government Policies to promote private Sector. Information Management and Business Review. 2010;1(2):79-87.

6. Klint $\mathrm{R}$, Long $\mathrm{H}$. Towards a definition of QualityHealthcare. Physician Executive 1(5)

7. Gangadharan (2008), Policy Reforms and Healthcare System in Kerala: Constraints and Options, Journal of Health and Development, Vol. 4, No. 1, pp: 195-207

8. Itumalla R (2012). Information Technology and Service Quality in Health Care: An Empirical Study of Private Hospital in India, International Journal of Innovation, Management and Technology, Vol. 3, No. 4, pp: 433-436.

9. Sharma KJ and Narang R (2011). Quality of Healthcare Services in Rural India: The User Perspective, Vikalpa, Vol. 36, No. 1, pp: 51-60

10. Ross M. Encylopedia of health Services Research USA: Sage publication Inc 2009 p. 664.
11. NABH \& NABL ACCREDITATION ASSISTANCE, ACME Consulting. www.acmeconsulting.in. (Accessed on 2-611).

12. NABH ACCREDITATION: CHOOSING THE RIGHT HOSPITAL. By Akash Rajpalin Simple Rules Discuss/11 May 2008. www.completewellbeing.com/article/nabhaccreditation-choosing-the-right-hospital. (accessed on 2-6-11).

13. Guidelines for Quality Accreditation: By Rashi Agarwal. www.qualitydigest.com/inside/health-carearticle/guideline-quality-accreditation-hospitals. (accessed on 2-6-11).

14. http://www.qcin.org/nabh/intro.php accessed on 29 March, 2010).

15. http://www.corpaxis.com/management-systemscertifications-services/nabh-accreditation/accessed on 29 March, 2010).

16. http://www.hiranandanihospital.org/hr_NABH.htm, accessed on 29 March, 2010.

17. El-Jardali F, Jamal D, Dimassi H, Ammar W, Tchaghchaghian V. The impact of hospital accreditation on quality of care: perception of Lebanese nurses, International Journal for Quality Health Care; 2008 Oct;20(5):363-71, accessed on 29 March, 2010, http://www.ncbi.nlm.nih.gov/pubmed/18596050?ordi nalpos=1\&itool=EntrezSystem2.PEntrez.Pubmed.Pubm ed_ResultsPanel.Pubmed_MultiItemSupl.Pubmed_TitleS earch\&linkpos=1\&\&log $\$=$ pmtitlesearch 4

18. Gentile S, Tardieu S, Vignally P, Mendizabal H, Raufaste C, Jouve E, et al. Accreditation knowledge acquired by personnel in the Marseille Hospital. Sante Publique. 2002 Sep;14(3):243-52, accessed on 29 March 2010, http://www.ncbi.nlm.nih.gov/pubmed/12564049.

19. Medknow Publications 2014-07-01 http://www. nabh. ind.in/text.asp?2014/1/2/29/151294 en Copyright 2015. The Journal of National Accreditation Board for Hospitals \& Healthcare Providers: oai:medknow.com: 151296 2014-07-01 all journal:J_Nat_Accred_Board_ Hosp_Healthcare_Providers. 